0.98 vs $4.90 \pm 0.74)$ in the AZD9567 group versus the prednisolone group. There was no statistically significant or clinically meaningful (i.e. > 1.2) difference in change from baseline to day 15 in DAS28-CRP between AZD9567 and prednisolone, although this was numerically lower with AZD9567 (Table 1). Similar results were observed for TJC68, SJC66, CRP and GH (Table 1). The proportions of patients achieving ACR20, 50 and 70 response criteria were similar in both groups, albeit numerically lower with AZD9567. Similar numbers of patients in each group reported treatment-emergent adverse events (AZD9567, $n=10$, prednisolone, $n=9$ ); most were mild in severity. One serious adverse event, suicidal depression, was reported after completing AZD9567 treatment. Morning fasting serum sodium/potassium ratio at day 15 was not altered with AZD9567 but was increased from baseline with prednisolone (Figure 1).

Conclusion: AZD9567 $40 \mathrm{mg}$ had a similar efficacy profile to prednisolone $20 \mathrm{mg}$ in patients with active RA. Both drugs were well tolerated, with no new safety signals. Unlike prednisolone, AZD9567 had no effect on serum sodium/potassium ratio, suggesting selectivity of AZD9567 for the GR over the MR. These results support further trials of AZD9567 in patients with inflammatory disease.

Acknowledgements: Medical writing support was provided by Richard Claes PhD of PharmaGenesis London, London, UK, funded by AstraZeneca, Gothenburg, Sweden in accordance with Good Publication Practice 3 (GPP3) guidelines (http://www.ismpp.org/gpp3).

This study was funded by AstraZeneca. AZD9567 is an investigational medical product with no approved indication.

Disclosure of Interests: Jacob M. van Laar Consultant of: Honoraria from - Abbvie, Arxx Tx, Galapagos, Gesyntha, Leadiant, Magenta, Roche, Sanofi Genzyme, Grant/research support from: AstraZeneca, Pfizer, Roche, Alejhandra Lei Shareholder of: AstraZeneca., Grant/research support from: Boehringer Ingelheim in 1998, Bristol-Myers Squibb in 1999, Employee of: AstraZeneca. Past employee of Almirall, Grünenthal, Boehringer Ingelheim, CESIF Pharma, Mary Safy-Khan Grant/research support from: Student grant from AstraZeneca 2015-2018., Joachim Almquist Shareholder of: AstraZeneca, Consultant of: AstraZeneca., Employee of: AstraZeneca., Carol Astbury Shareholder of: AstraZeneca., Employee of: AstraZeneca., Maria Belvisi Shareholder of: AstraZeneca., Grant/research support from: AstraZeneca and Chiesi, Employee of: AstraZeneca., Adam Platt Shareholder of: AstraZeneca., Employee of: AstraZeneca., Susanne Prothon Shareholder of: AstraZeneca., Employee of: AstaZeneca., Sara Samuelsson Shareholder of: AstraZeneca, Employee of: AstraZeneca, Petter Svanberg Employee of: AstraZeneca, Christina Keen Shareholder of: AstraZeneca., Employee of: AstraZeneca.

DOI: 10.1136/annrheumdis-2021-eular.632

\section{POS0090 RISK OF QT INTERVAL PROLONGATION ASSOCIATED WITH CHRONIC USE OF HYDROXYCHLOROQUINE IN RHEUMATIC PATIENTS AND THE EFFECT OF COTREATMENTS}

M. Antivalle ${ }^{1}$, G. La Paglia ${ }^{1}$, M. C. Ditto ${ }^{2}$, S. Parisi ${ }^{2}$, E. Fusaro ${ }^{2}$, M. Agosti ${ }^{3}$, P. Sarzi Puttini ${ }^{1} .{ }^{1}$ L. Sacco Universty Hospital, Rheumatology, Milano, Italy; ${ }^{2}$ AOU Città della Salute e della Scienza di Torino; Rheumatology Unit; Department of Medical Science, Torino, Italy; ${ }^{3}$ Azienda Socio-Sanitaria Territoriale (ASST) di Vimercate, Department of Medical Science, Vimercate, Italy

Background: Hydroxychloroquine (HCQ) has been used safely for over 60 years in rheumatic patients. However, following its recent use in covid-19 disease, its safety has been questioned, following controversial reports of cardiac toxicity ${ }^{1}$, possibly related to a prolongation of the QT interval ${ }^{2}$.

Objectives: To explore the influence of chronic treatment with hydroxychloroquine on QT interval in rheumatic patients, and the possible effects of drug-todrug interference ${ }^{3}$.

Methods: 12-lead electrocardiogram tracings were recorded with standard equipment in 229 ambulatory patients ( $S L E=53, \mathrm{RA}=52, \mathrm{SSc}=56$, $\mathrm{UCTD}=38$, Others $=30$ ). The present analysis was performed on corrected QT intervals (QTc) calculated according to Framingham formula $(\mathrm{QTC}=\mathrm{QT}+0.154$ $(1-R R)$ ), with ULN $=449 \mathrm{~ms}$ in males, and $467 \mathrm{~ms}$ in females. Estimated glomerular filtrate rate (eGFR) was calculated from serum creatinine with the CKD-EPI equation. The influence on QTc values of demographic variables, chronic ( $\geq 3$ months) HCQ treatment, and of the use of selected comedications -Statins, Angiotensin Converting Enzyme inhibitors (ACEi), Angiotensin Receptor Blockers (ARBs), Selective Serotonin Reuptake Inhibitors (SSRIs), Proton-Pump Inhibitors (PPI), Calcium Channel Blockers (CCBs) - were evaluated by parametric or non parametric statistical methods, as appropriate. All statistic al analyses were performed with the IBM SPSS statistical package version 25 .

\section{RESULTS:}

Table 1. Demographic and clinical variables in patients treated with $\mathrm{HCQ}$ (HCQ+) and in controls (HCQ-).

\begin{tabular}{|c|c|c|c|c|c|c|c|c|c|c|}
\hline & \multirow[t]{3}{*}{$\mathrm{N}$} & Age & Female & eGFR & Statins & ACEi & ARB & SSRI & PPI & $\mathrm{CCB}$ \\
\hline & & Yrs & $\mathrm{N}$ & $\mathrm{mL} / \mathrm{min} / 1.73 \mathrm{~m}^{2}$ & $\mathrm{~N}$ & $\mathrm{~N}$ & $\mathrm{~N}$ & $\mathrm{~N}$ & $\mathrm{~N}$ & $\mathrm{~N}$ \\
\hline & & $\pm \mathrm{SD}$ & $\%$ & & $\%$ & $\%$ & $\%$ & $\%$ & $\%$ & $\%$ \\
\hline \multirow[t]{2}{*}{ All } & 229 & 58.02 & 206 & 87.14 & 29 & 48 & 19 & 14 & 138 & 30 \\
\hline & & \pm 14.36 & 90.0 & 18.96 & 12.7 & 21.8 & 8.3 & 6.1 & 60.3 & 13.1 \\
\hline \multirow[t]{2}{*}{$\mathrm{HCQ}+$} & 132 & 58.71 & 122 & 87.00 & 18 & 32 & 11 & 9 & 80 & 17 \\
\hline & & \pm 14.49 & 92.4 & 20.04 & 13.6 & 24.2 & 8.3 & 6.8 & 60.6 & 12.9 \\
\hline \multirow[t]{2}{*}{ HCQ- } & 97 & 57.51 & 84 & 87.32 & 11 & 16 & 8 & 5 & 58 & 13 \\
\hline & & \pm 14.30 & 86.6 & 17.47 & 11.3 & 16.5 & 8.2 & 5.2 & 59.8 & 13.4 \\
\hline $\mathrm{p}$ & & 0.532 & 0.183 & 0.897 & 0.690 & 0.189 & 1.000 & 0.782 & 1.000 & 1.000 \\
\hline
\end{tabular}

Demographic variables, and the use of evaluated comedications were not different in HCQ+ and HCQ- patients (Table 1). In the whole population, the QTc mean duration was $416.72 \pm$ $20.70 \mathrm{~ms}$, and was correlated with age $(r=0.215, p=0.001)$, but not with gender $(p=0.548)$, eGFR $(r=-0.93, p=0.163)$, or disease $(p=0.092)$. In only 4 patients $(H C Q+: 3(2.3 \%)-$ HCQ-: $1(1 \%), p=0.639)$ QTc duration was above ULN.

QTc duration was not associated with the use of Statins, ACEi, ARBs, or SSRIs ( $p=0.454,0.276,0.475$, and 0.131 respectively), but was significantly prolonged in patients treated with $\mathrm{HCQ}(421.26 \pm 19.19$ vs $410.55 \pm 21.18 \mathrm{msec}$ $\mathrm{p}<0.001)$, PPIs $(420.57 \pm 21.45$ vs $410.89 \pm 18.12 \mathrm{~ms}, \mathrm{p}<0.001)$, and CCBs $(424.22 \pm 25.97$ vs $415.59 \pm 19.62 \mathrm{~ms}, \mathrm{p}<0.033)$. Furthermore, as reported in Fig. 1, our data show a trend - albeit not statistically significant - towards an additive effect on QT prolongation of the association of PPIs and CCBs with $\mathrm{HCQ}$, even more evident in the case of association of the 3 drug classes.

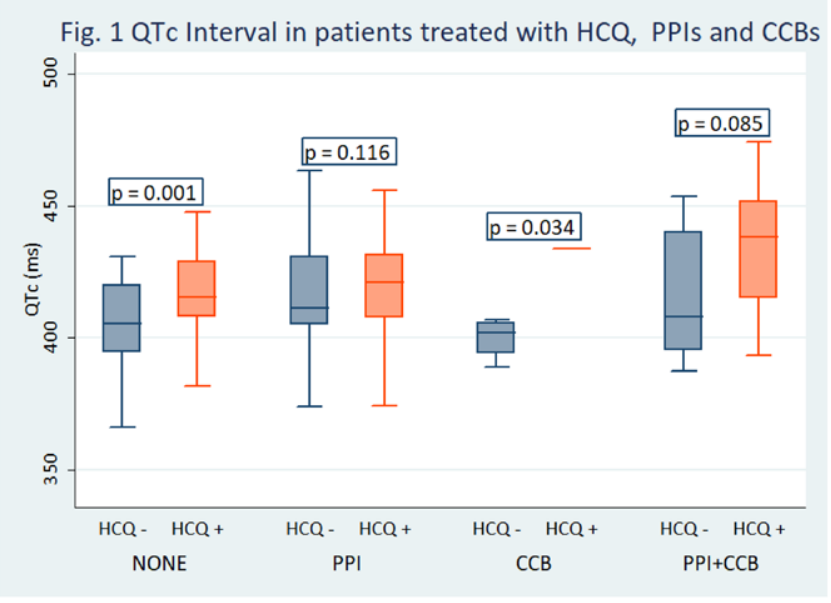

Conclusion: In this study, the QTc interval was significantly prolonged in patients treated with hydroxychloroquine as compared to controls, although significant prolongation was extremely infrequent. Furthermore, our data revealed signs of drug-drug interference, suggesting that regular monitoring of the electrocardiogram is advisable in these patients, often undergoing cotreatment with multiple drugs.

REFERENCES:

[1] Imad M. Tleyjeh, et al. The Cardiac Toxicity of Chloroquine or Hydroxychloroquine in COVID-19 Patients: A Systematic Review and Meta-regression Analysis. Mayo Clin Proc Innov Qual Outcomes. 2020 Nov 2 doi: 10.1016/j. mayocpiqo.2020.10.005 [Epub ahead of print].

[2] Teodoro J. Oscanoa, et al. Frequency of Long QT in Patients with SARS CoV-2 Infection Treated with Hydroxychloroquine: A Meta-analysis. Int J Antimicrob Agents.

[3] Byung Jin Choi, et al. Risk of QT prolongation through Drug-drug Interactions between Hydroxychloroquine and Concomitant Drugs Prescribed in Real-world Practice. Preprint from Research Square, 22 Sep 2020 DOI: 10.21203/rs.3.rs-79572/v1 PPR: PPR217328.

Disclosure of Interests: None declared

DOI: 10.1136/annrheumdis-2021-eular.738 